\title{
Monoclonal Antibody for an Outer Membrane Lipoprotein of the Pseudomonas fluorescens Group of the Family Pseudomonadaceae
}

\author{
L. M. MUTHARIA AND ROBERT E. W. HANCOCK* \\ Department of Microbiology, University of British Columbia, Vancouver, British Columbia, Canada V6T IW5
}

\begin{abstract}
Monoclonal antibody MA1-6 directed against Pseudomonas aeruginosa strain PAO1 outer membrane lipoprotein $\mathrm{H} 2$ also interacted with a protein having an identical molecular weight from 50 of 52 strains of $P$. aeruginosa tested. This antibody interacted with the $P$. fluorescens group of the family Pseudomonadaceae and with Azotobacter vinelandii but not with several other species of gram-negative bacteria. A colony blotting assay performed with this antibody allowed rapid detection of the $P$. fluorescens- $A$. vinelandii group.
\end{abstract}

Currently, the identification of Pseudomonas species in clinical laboratories requires a large number of biochemical tests $(12,13)$. These methods are time consuming, and some tests, especially those used to differentiate glucose-oxidizing Pseudomonas species, are not entirely satisfactory $(6,12$, 13). In recent years techniques that involve determinations of deoxyribonucleic acid base composition (4), deoxyribonucleic acid-deoxyribonucleic acid hybridization (10), ribonucleic acid homology $(1,11)$, or fatty acid composition $(6,7)$ have been developed. Although these techniques have provided useful information for taxonomic grouping of $P$ seudomonas species, they involve expensive reagents or equipment or both and therefore are not readily applicable in clinical laboratories. Thus, there is need for new methods for rapid identification of groups of these bacteria. In this paper we describe the use of a monoclonal antibody specific for a single antigenic epitope on outer membrane protein $\mathrm{H} 2$ of Pseudomonas aeruginosa as an identification tool.

Monoclonal antibody MA1-6 was obtained from fusion of NS-1 myeloma cells and spleen cells from a mouse immunized with $P$. aeruginosa PAO1 outer membranes (3). This antibody interacted in enzyme-linked immunosorbent assays with strain PAO1 outer membranes and in Western immunoblots with outer membrane peptidoglycan associatedlipoprotein $\mathrm{H} 2$ of $P$. aeruginosa (2) (Fig. 1A). The antigenic epitope recognized by monoclonal antibody MA1-6 was present on lipoprotein $\mathrm{H} 2$ in the outer membranes from all 17 International Antigen Typing Scheme serotype strains tested (Fig. 1A) and from 28 isolates of $P$. aeruginosa from cystic fibrosis patients. ( $P$. aeruginosa type strain ATCC 10145 was not examined in this study.)

To test for the conservation of antigenic epitopes recognized by monoclonal antibody MA1-6 among Pseudomonas species and other gram-negative bacteria, the antibody was tested against outer membranes isolated from several other species by both the enzyme-linked immunosorbent assay (9) and the Western immunoblot technique (9) (Table 1).

The cross-reactivity of monoclonal antibody MA1-6 was demonstrated with an outer membrane protein having a molecular weight similar to that of lipoprotein $\mathrm{H} 2$ of $P$. aeruginosa in Western immunoblots of outer membranes from Pseudomonas chlororaphis ATCC $9446^{\mathrm{T}}$ (T $=$ type strain), Pseudomonas fluorescens ATCC 949 and ATCC $13525^{\mathrm{T}}$, Pseudomonas putida ATCC 4359 and ATCC $12633^{\mathrm{T}}$, and Pseudomonas syringae ATCC $19310^{\mathrm{T}}$, with a protein having a higher molecular weight in Pseudomonas stutzeri ATCC $17588^{\mathrm{T}}$, Pseudomonas anguilliseptica ET2 and

\footnotetext{
* Corresponding author.
}

ET7601, and Azotobacter vinelandii OP, and with a protein having a slightly lower molecular weight in Pseudomonas aureofaciens ATCC $13985^{\mathrm{T}}$ outer membranes (Fig. 1B). There was no interaction with outer membranes from Pseudomonas cepacia ATCC 25416, Pseudomonas solanacearum ATCC $11696^{\mathrm{T}}$, Pseudomonas acidovorans ATCC 9353, Pseudomonas maltophilia ATCC $13637^{\mathrm{T}}$, Escherichia coli CGSC 6044 and PC0479, or Salmonella typhimurium LT2 SGSC 205 and SGSC 206 or with outer membranes from any strain belonging to the Vibrionaceae or Aeromonas group (Table 1).

TABLE 1. Cross-reactivities of monoclonal antibody MA1-6 specific for $P$. aeruginosa outer membrane lipoprotein $\mathrm{H} 2$

\begin{tabular}{|c|c|c|c|}
\hline \multirow[b]{2}{*}{ Antigen from: } & \multicolumn{3}{|c|}{ Cross-reactivity } \\
\hline & $\begin{array}{c}\text { ELISA } \\
\text { reading } \\
\text { (absorbance at } \\
405 \mathrm{~nm})^{a}\end{array}$ & $\begin{array}{l}\text { Western } \\
\text { immunoblot }\end{array}$ & $\begin{array}{l}\text { Colony } \\
\text { blot }\end{array}$ \\
\hline$P$. aeruginosa (50 strains) & $1.2-0.4$ & + & + \\
\hline $\begin{array}{l}\text { P. putida ATCC } 4359 \text { and } \\
\text { ATCC } 12633^{\mathrm{T}}\end{array}$ & $0.4,0.6$ & + & + \\
\hline$P$ syringae ATCC $19310^{\mathrm{T}}$ & 0.4 & + & + \\
\hline P. chlororaphis ATCC $9446^{\mathrm{T}}$ & 0.3 & + & + \\
\hline P. aureofaciens ATCC $13985^{\mathrm{T}}$ & 0.1 & + & + \\
\hline P. stutzeri ATCC $17588^{\mathrm{T}}$ & 0.3 & + & + \\
\hline $\begin{array}{l}\text { P. fluorescens ATCC } 949 \text { and } \\
\text { ATCC } 13525^{\mathrm{T}}\end{array}$ & $0.5,0.5$ & + & + \\
\hline $\begin{array}{l}P . \text { anguilliseptica } \mathrm{ET} 2 \text { and } \\
\text { ET7601 }\end{array}$ & $0.1,0.15$ & + & + \\
\hline Azotobacter vinelandii $\mathrm{OP}$ & 0.1 & + & + \\
\hline P. maltophilia ATCC $13637^{\mathrm{T}}$ & - & - & - \\
\hline P. acidovorans ATCC 9353 & - & - & - \\
\hline $\begin{array}{l}P . \text { solanacearum ATCC } \\
11696^{\mathrm{T}}\end{array}$ & - & - & - \\
\hline $\begin{array}{l}\text { Pseudomonas pseudomallei } \\
\quad \text { ATCC } 23343^{\mathrm{T}}\end{array}$ & - & - & - \\
\hline$P$ cepacia ATCC 25416 & - & - & - \\
\hline $\begin{array}{l}\text { Escherichia coli CGSC } 6044 \\
\text { and PC0 } 479\end{array}$ & - & - & - \\
\hline $\begin{array}{l}\text { S. typhimurium LT2 SGSC } 205 \\
\text { and SGSC } 206\end{array}$ & - & - & - \\
\hline Edwardsiella tarda E79054 & - & - & - \\
\hline $\begin{array}{l}\text { Vibrio anguillarum ET208 and } \\
\text { HT7602 }\end{array}$ & - & - & - \\
\hline $\begin{array}{l}\text { Aeromonas salmonicida } \\
\text { NCMB } 2020\end{array}$ & - & - & - \\
\hline Aeromonas hydrophila ЕТ2 & - & - & - \\
\hline
\end{tabular}

${ }^{a}$ ELISA, Enzyme-linked immunosorbent assay. 

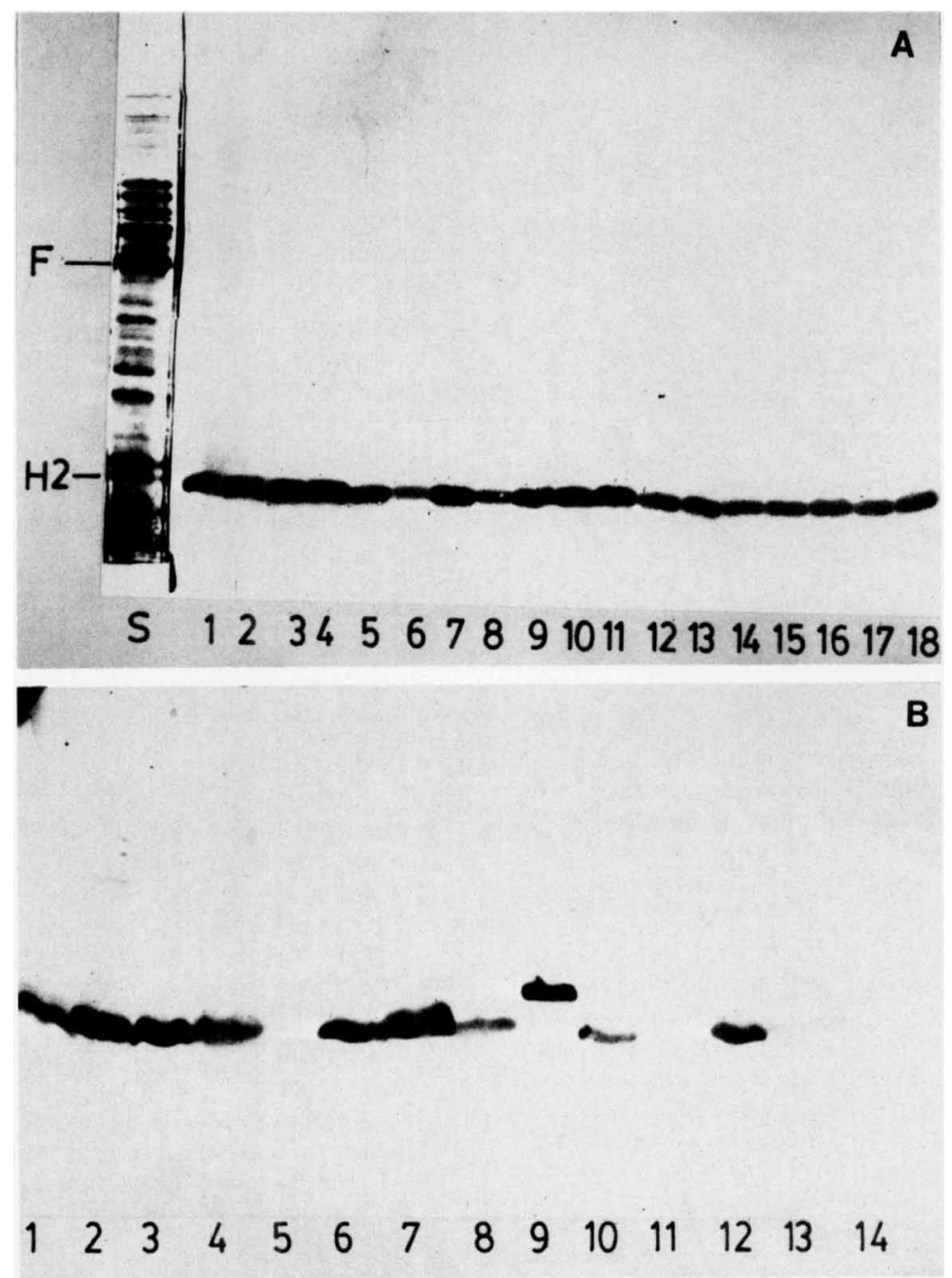

FIG. 1. (A) Western electrophoretic blots of outer membranes of the serotyping strains of $P$. aeruginosa. The blots were treated with antibody MA1-6, followed by goat anti-mouse alkaline phosphatase-conjugated antibody and addition of the substrate (napthol AS MX phosphoric acid and Fast Red TR salt). Lane S, amido black-stained outer membrane profile of our laboratory wild-type strain H103; lane 1, serotype 1 ; lane 2 , serotype 2 ; lane 3, serotype 3 ; lane 4, serotype 4 ; lane 5 , serotype 5 ; lane 6 , serotype 6 ; lane 7 , serotype 7 ; lane 8 , serotype 8 ; lane 9, serotype 9 ; lane 10 , serotype 10; lane 11 , serotype 11 ; lane 12 , serotype 12 ; lane 13 , serotype 13 ; lane 14 , serotype 14 ; lane 15 , serotype 15; lane 16, serotype 16; lane 17, serotype 17; lane 18, purified lipoprotein $\mathrm{H} 2$. Only one band was labeled. Lane S is a sodium dodecyl sulfate-polyacrylamide gel electrophoretogram of $P$. aeruginosa strain $\mathrm{H} 103$ outer membrane proteins stained with Coomassie blue. (B) Western electrophoretic blot showing interaction of monoclonal antibody MA1-6 with outer membranes from $P$. anguilliseptica ET2 (lane 1), $P$. aeruginosa strain H103 (lane 2), P. fluorescens ATCC 949 (lane 3), $P$. syringae ATCC $19310^{\mathrm{T}}$ (lane 4), $P$. aeruginosa CF46nm (lane 5), $P$. putida ATCC $12633^{\mathrm{T}}$ (lane 6), P. stutzeri ATCC $17588^{\mathrm{T}}$ (lane 7 ), P. aeruginosa ATCC 8689 (lane 8), Azotobacter vinelandii OP (lane 9 ), $P$. aureofaciens ATCC $13985^{\mathrm{T}}$ (lane 10), $P$. cepacia ATCC 25416 (lane 11), $P$. chlororaphis ATCC $9446^{\mathrm{T}}$ (lane 12), $P$. pseudomonallei ATCC $23343^{\mathrm{T}}$ (lane 13), and P. aeruginosa ATCC 9721 (lane 14). The blot was developed as described above.

Similar results were obtained by using a colony immunoblot technique (Fig. 2 and Table 1). In this technique, bacterial colonies were transferred from agar plates onto prewashed nitrocellulose paper by contact. After incubation of the filters at $30^{\circ} \mathrm{C}$ for $30 \mathrm{~min}$, the colony blots were incubated for $45 \mathrm{~min}$ at $37^{\circ} \mathrm{C}$ with tris(hydroxymethyl)aminomethane-buffered saline [TBS; $10 \mathrm{mM}$ tris(hydroxymethyl)aminomethane hydrochloride, $\mathrm{pH} \mathrm{7.4,2}$ $\mathrm{mM} \mathrm{MgCl}, 100 \mathrm{mM} \mathrm{NaCl}$ ] containing 3\% (wt/vol) gelatin and then for $2 \mathrm{~h}$ with the test antibody (MA1-6) diluted in TBS containing $1 \%(\mathrm{wt} / \mathrm{vol})$ gelatin. The blots were subsequently washed three times by incubation for $15 \mathrm{~min}$ in TBS containing $0.1 \%$ (wt/vol) gelatin and then were incubated for $2 \mathrm{~h}$ at $37^{\circ} \mathrm{C}$ with a goat anti-mouse immunoglobulin coupled to horseradish peroxidase (Flow Laboratories, Inc.,
McLean, Va.). After washing as described above, the blots were developed by using a histochemical substrate for peroxidase $(5 \mathrm{mg}$ of 4-chloro-1-napthol dissolved in $1.67 \mathrm{ml}$ of ice-cold absolute methanol and mixed at $23^{\circ} \mathrm{C}$ with $10 \mathrm{ml}$ of TBS containing $5 \mu \mathrm{l}$ of $30 \%$ [ $\mathrm{vol} / \mathrm{vol}] \mathrm{H}_{2} \mathrm{O}_{2}$ ). Cell surfacelocalized components could be differentiated from nonsurface accessible components (which included protein $\mathrm{H} 2$ ) by varying the concentration of $\mathrm{NaCl}$ in the TBS from 1 to $100 \mathrm{mM}(9 \mathrm{a})$. The colony immunoblot technique provided a rapid and sensitive screening procedure by which a large number of bacterial strains could be tested in a short time.

In agreement with the data described above, Mizuno and Kageyama (5) demonstrated immunoprecipitation of a lipoprotein from the outer membranes of $P$. fluorescens and $P$. putida by using a polyclonal antiserum against $P$. aeruginosa 


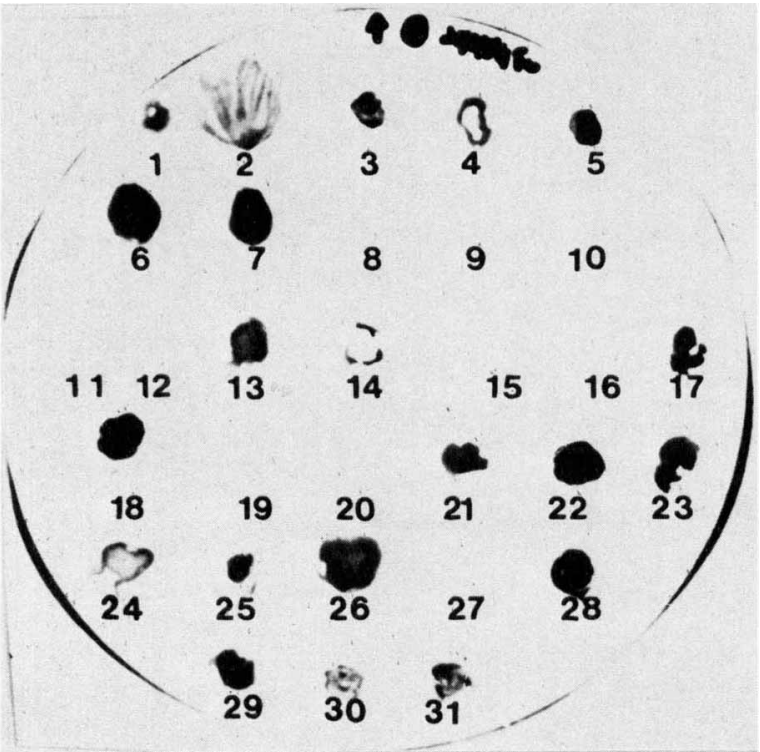

FIG. 2. Colony immunoblot showing interaction of monoclonal antibody MA1-6 specific for protein $\mathrm{H} 2$ of $P$. aeruginosa with the following strains: $1, P$. aeruginosa strain $\mathrm{P} 1$ nonmucoid; $2, P$. aeruginosa strain P1 mucoid; 3 and 4, $P$. fluorescens ATCC 949 and ATCC $13525^{\mathrm{T}}$, respectively; $5, P$. aeruginosa $\mathrm{PAO} 1$ strain $\mathrm{H} 103 ; 6$, $P$. aeruginosa strain $\mathrm{Cl}$ mucoid; $7, P$. aeruginosa strain $\mathrm{C} 1$ nonmucoid; 8, 9, and 10, Escherichia coli strains CGSC 6041, CGSC 6044 , and PC0479, respectively; $11, P$. pseudomallei ATCC $23343^{\mathrm{T}}$; 12, $P$. solanacearum ATCC $11696^{\mathrm{T}} ; 13$ and $14, P$. putida ATCC 4359 and ATCC $12633^{\mathrm{T}}$, respectively; 15 and $16, S$. typhimurium LT2 strains SGSC 206 and SGSC 227, respectively; 17, $P$. aeruginosa ATCC $8689 ; 18, P$. aeruginosa PAO1 strain H103; 19, Aeromonas salmonicida NCMB 2020;20, Aeromonas hydrophila ET2; 21, P chlororaphis ATCC $9446^{\mathrm{T}} ; 22, P$. aeruginosa ATCC $19305^{\mathrm{T}} ; 23, P$. aeruginosa strain $\mathrm{Z61} ; 24, P$. aureofaciens ATCC $13985^{\mathrm{T}} ; 25, P$. syringae ATCC $19310^{\mathrm{T}} ; 26, P$. aeruginosa $\mathrm{CF} 4349 ; 27, P$. maltophilia ATCC $13637^{\mathrm{T}} ; 28, P$. stutzeri ATCC $17588^{\mathrm{T}} ; 29, P$. aeruginosa strain $\mathrm{H} 223 ; 30$ and $31, P$. aeruginosa strains AK1012 and AK1282, respectively. Colonies were transferred from agar plates onto nitrocellulose paper and incubated with $3 \%$ gelatin and then with the monoclonal antibody; this was followed by treatment with goat anti-mouse immunoglobulin coupled to horseradish peroxidase and addition of the substrate (4-chloro-1-napthol and $\mathrm{H}_{2} \mathrm{O}_{2}$ ).

lipoprotein H2. Recently, Palleroni et al. and DeVos and DeLey suggested that the family Pseudomonadaceae consists of a number of distantly related taxonomic groups of bacteria. The bacteria with which monoclonal antibody MA1-6 interacted were placed in the $P$. fluorescens group (also called group 1 pseudomonads); the other Pseudomonas species which did not interact with the antibody were placed in taxonomically distinct groups $(1,10,11)$. In comparison with these data, monoclonal antibody MA5-8, which is specific for outer membrane protein $\mathrm{F}$, interacted only with $P$. aeruginosa strains (9a), whereas lipopolysaccharide lipid A-specific monoclonal antibody $5 \mathrm{E} 4$ interacted with almost all of the gram-negative bacteria tested (8).

The results presented here support the taxonomic data obtained from ribosomal ribonucleic acid homology studies suggesting that Azotobacter vinelandii is taxonomically related to the $P$. fluorescens group of the family Pseudomonadaceae (1). Thus, monoclonal antibody MA1-6 showed specific interaction with outer membranes and col- onies of strains belonging to a single taxonomic subdivision, the group 1 pseudomonads ( $P$. fluorescens group), indicating that this antibody has a potential role in the rapid identification of these strains and in taxonomic studies. However, it should be noted that such a method cannot serve as the sole criterion for species identification since a point mutant resulting in loss of the specific antigenic site on protein $\mathrm{H} 2$ could cause inaccurate identification. Indeed, we have identified two $P$. aeruginosa strains, strain ATCC 9721 (Fig. 1B, lane 14) and an isolate from a patient with cystic fibrosis, which lacked protein $\mathrm{H} 2$ on sodium dodecyl sulfatepolyacrylamide gels and failed to interact with antibody MA1-6. Nevertheless, these 2 strains provided the only exceptions among the $52 P$. aeruginosa strains examined to date. Thus, we feel that monoclonal antibody MA1-6 provides a useful screening tool for the $P$. fluorescens group of the family Pseudomonadaceae. We are currently attempting to deposit this antibody with the American Type Culture Collection.

This work was funded by the Medical Research Council and the Natural Science and Engineering Research Council.

\section{LITERATURE CITED}

1. DeVos, P., and J. DeLey. 1983. Intra- and intergenic similarities of Pseudomonas and Xanthomonas ribosomal ribonucleic acid cistrons. Int. J. Syst. Bacteriol. 33:487-509.

2. Hancock, R. E. W., R. T. Irvin, J. W. Costeron, and A. M. Carey. 1981. Pseudomonas aeruginosa outer membrane: peptidoglycan-associated protein. J. Bacteriol. 145:628-631.

3. Hancock, R. E. W., A. A. Wieczorek, L. M. Mutharia, and K. Poole. 1982. Monoclonal antibodies against Pseudomonas aeruginosa outer membrane antigens: isolation and characterization. Infect. Immun. 37:166-171.

4. Mandel, M. 1966. Deoxyribonucleic acid composition in the genus Pseudomonas. J. Gen. Microbiol. 43:273-292.

5. Mizuno, T., and M. Kageyama. 1978. Separation and characterization of the outer membrane of Pseudomonas aeruginosa. J. Biochem. 84:179-191.

6. Moss, C. W., and S. B. Dees. 1976. Cellular fatty acids and metabolic products of Pseudomonas species obtained from clinical specimens. J. Clin. Microbiol. 4:492-502.

7. Moss, C. W., S. B. Samuels, and R. E. Weaver. 1972. Cellular fatty acid composition of selected Pseudomonas species. Appl. Microbiol. 24:596-598

8. Mutharia, L. M., G. Crockford, W. C. Bogard, and R. E. W. Hancock. 1984. Monoclonal antibodies specific for Escherichia coli J-5 lipopolysaccharide: cross-reaction with other gramnegative bacterial species. Infect. Immun. 45:631-636.

9. Mutharia, L. M., and R. E. W. Hancock. 1983. Surface localization of Pseudomonas aeruginosa outer membrane porin protein $\mathrm{F}$ using monoclonal antibodies. Ínfect. Immun. 42:105-112.

9a.Mutharia, L. M.; and R. E. W. Hancock. 1985. Characterization of two surface-localized antigenic sites on porin protein $F$ of Pseudomonas aeruginosa. Can. J. Microbiol. 31:381-386.

10. Palleroni, N. J., R. W. Ballard, E. Ralston, and M. Duodoroff. 1972. Deoxyribonucleic acid homologies among some Pseudomonas species. J. Bacteriol. 110:1-11.

11. Palleroni, N. J., R. Kunisawa, R. Contopoulou, and M. Duodoroff. 1973. Nucleic acid homologies in the genus Pseudomonas. Int. J. Syst. Bacteriol. 23:333-339.

12. Pickett, M. J., and M. M. Pedersen. 1970. Characterization of saccharolytic nonfermentative bacteria associated with man. Can. J. Microbiol. 16:351-362.

13. Pickett, M. J., and M. M. Pederson. 1970. Salient features of nonsaccharolytic and weakly saccharolytic nonfermentative rods. Can. J. Microbiol. 16:401-409. 